\title{
The Prox1-Vegfr3 feedback loop maintains the identity and the number of lymphatic endothelial cell progenitors
}

\author{
R. Sathish Srinivasan, ${ }^{1,5,7}$ Noelia Escobedo, ${ }^{1,7}$ Ying Yang, ${ }^{1,6,7}$ Ashley Interiano, ${ }^{1}$ Miriam E. Dillard, ${ }^{1}$ \\ David Finkelstein, ${ }^{2}$ Suraj Mukatira, ${ }^{2}$ Hyea Jin Gil, ${ }^{1}$ Harri Nurmi, ${ }^{3,4}$ Kari Alitalo, ${ }^{3,4}$ \\ and Guillermo Oliver ${ }^{1}$ \\ ${ }^{1}$ Department of Genetics, ${ }^{2}$ Department of Computational Biology, St. Jude Children's Research Hospital, Memphis, Tennessee \\ 38105, USA; ${ }^{3}$ Wihuri Research Institute, ${ }^{4}$ Translational Cancer Biology Program, University of Helsinki, Helsinki 00014, \\ Finland
}

\begin{abstract}
The mammalian lymphatic vasculature is important for returning fluids from the extracellular tissue milieu back to the blood circulation. We showed previously that Prox1 dosage is important for the development of the mammalian lymphatic vasculature. The lack of Prox1 activity results in the complete absence of lymphatic endothelial cells (LECs). In Prox1 heterozygous embryos, the number of LECs is reduced because of a decrease in the progenitor pool in the cardinal vein. This reduction is caused by some progenitor cells being unable to maintain Prox1 expression. In this study, we identified Vegfr3, the cognate receptor of the lymphangiogenic growth factor Vegfc, as a dosage-dependent, direct in vivo target of Prox1. Using various mouse models, we also determined that Vegfr3 regulates Prox1 by establishing a feedback loop necessary to maintain the identity of LEC progenitors and that Vegfc-mediated activation of Vegfr3 signaling is necessary to maintain Prox1 expression in LEC progenitors. We propose that this feedback loop is the main sensing mechanism controlling the number of LEC progenitors and, as a consequence, the number of budding LECs that will form the embryonic lymphatic vasculature.
\end{abstract}

[Keywords: Prox1; Vegfr3; lymphatics; endothelial cell; progenitor; mouse]

Supplemental material is available for this article.

Received February 18, 2013; revised version accepted August 21, 2014.

In the mammalian embryo, lymphatic endothelial cells (LECs) originate from the embryonic veins during a brief period (mouse embryonic days 9.75-13.5 [E9.75-E13.5]) (Srinivasan et al. 2007). The nuclear hormone receptor Coup-TFII and the Sry-related homeobox transcription factor Sox18 are both required to activate the expression of the prospero-related homeobox transcription factor Prox1 in a subpopulation of venous ECs. This step leads to the formation of the initial Proxl-expressing LEC progenitors in the cardinal vein $(\mathrm{CV})$ (Francois et al. 2008; Srinivasan et al. 2010). Subsequently, most of these progenitors bud from the $\mathrm{CV}$ and express additional genes such as podoplanin (Yang et al. 2012; Hagerling et al. 2013). The small fraction of LEC progenitors that remain inside the CV help form the lymphovenous valve, which

Present addresses: ${ }^{5}$ Cardiovascular Biology Research Program, Oklahoma Medical Research Foundation, Oklahoma City, OK, 73104 USA; ${ }^{6}$ Division of Animal Sciences, Bond Life Sciences Center, University of Missouri, Columbia, MO 65211, USA.

${ }^{7}$ These authors contributed equally to this work.

Corresponding author: guillermo.oliver@stjude.org

Article is online at http://www.genesdev.org/cgi/doi/10.1101/gad.216226.113. is responsible for returning lymph fluid to the blood circulation (Srinivasan and Oliver 2011).

In vivo and in vitro data have highlighted the key roles of Prox1 during different stages of LEC differentiation and lymphatic vasculature formation. In Prox1-null embryos, LECs are absent (Wigle and Oliver 1999), and conditional deletion of Prox1 at any developmental or postnatal time point results in the loss of LEC identity and the reversal of these cells' identity to a blood EC (BEC)-like fate (Johnson et al. 2008). Ectopic expression of Proxl in BECs maintained in culture activates several LEC-specific genes, including podoplanin and Vegfr3 (Hong et al. 2002; Petrova et al. 2002). At the molecular level, the analysis of Prox1-null embryos in which the ORF of Prox1 was replaced with either $L a c Z$ or GFP reporter gene constructs revealed that Proxl maintains its own expression

\footnotetext{
(C) 2014 Srinivasan et al. This article is distributed exclusively by Cold Spring Harbor Laboratory Press for the first six months after the full-issue publication date (see http://genesdev.cshlp.org/site/misc/terms.xhtml). After six months, it is available under a Creative Commons License (Attribution-NonCommercial 4.0 International), as described at http:// creativecommons.org/licenses/by-nc/4.0/.
} 
in venous LEC progenitors (Wigle et al. 2002; Srinivasan et al. 2010). The expression of these reporter genes is normally activated in Prox1-null embryos but cannot be maintained (Wigle et al. 2002; Srinivasan et al. 2010).

Prox $^{+/-}$(Prox $^{+/ L a c Z}$ and Prox $\left.1^{+/ G F P C r e}\right)$ embryos display edema and occasionally develop blood-filled lymphatics (Harvey et al. 2005; Johnson et al. 2008; Srinivasan and Oliver 2011). Most of these animals die at birth due to chylothorax and chylous ascites (Harvey et al. 2005; Johnson et al. 2008; Srinivasan and Oliver 2011), and those that survive become obese with age (Harvey et al. 2005). We recently showed that Prox $1^{+/-}$mice have a reduced number of LEC progenitors and LECs and that the lymphovenous valves are absent (Srinivasan and Oliver 2011). Furthermore, we determined that the autoregulation of Prox1 expression is dose-dependent, and the number of Prox1-expressing LEC progenitors in the CV of Prox $1^{+/-}$ mice is reduced due to the decreased amount of available Coup-TFI/Prox1 protein complex during the early stages of Prox1 regulation in these cells (Srinivasan and Oliver 2011). This protein complex is known to regulate several LEC-specific genes, including the lymphangiogenic receptor tyrosine kinase Vegfr3 (Lee et al. 2009; Yamazaki et al. 2009; Aranguren et al. 2013).

Despite these facts, how Prox1 regulates itself or how Prox1 expression is regulated in LECs remains unknown. This knowledge is important, as it might provide us with clues about how the embryo controls the number of specified LEC progenitors in the CV and their subsequent budding. Our previous work failed to identify direct binding of Proxl to the Coup-TFII-binding site in the Prox1 regulatory element, excluding the possibility that the Coup-TFII/Prox1 protein complex directly regulates Prox1 expression. Alternatively, downstream targets of Prox1 might regulate Prox1 expression in a feedback manner; however, in vivo, Proxl targets in LECs have not yet been identified. Earlier in vitro work suggested that Vegfr3 is a Prox1 target (Petrova et al. 2002). Vegfr3 is expressed in all BECs until around E10.5, and, in its absence, mouse embryos die at around E10.0 with severe cardiovascular defects (Dumont et al. 1998). Later, its expression becomes restricted to LECs and the tips of growing blood vessels (Kaipainen et al. 1995; Dumont et al. 1998; Tammela et al. 2008; Nakayama et al. 2013). Vegfc is the best-characterized Vegfr3 ligand, and, in its absence, Prox $1^{+}$LEC progenitors fail to bud from the CV (Karkkainen et al. 2004). Similar to Prox $1^{+/-}$embryos, the number of LEC progenitors and LECs is reduced in both $\mathrm{Vegfr}^{+/-}$ and $V e g \mathrm{fC}^{+/-}$embryos (Hagerling et al. 2013), suggesting a functional relationship between Prox1 and Vegfr3.

In this study, we provide conclusive in vivo evidence to demonstrate that Vegfr3 is a dosage-dependent, direct Proxl target gene. We also report for the first time that Vegfr3 regulates Prox1 expression and establish the existence of a positive feedback loop between Proxl and Vegfr3 in LECs in vivo and in vitro. Finally, we show that $V e g f c$ signaling helps to maintain LEC progenitor identity and that, in Vegfc ${ }^{-/-}$embryos, Proxl expression fails to be maintained, resulting in the reduction in the number of Prox $1^{+}$LEC progenitors and hence the number of LECs.
We conclude that a defective Prox1-Vegfr3 regulatory loop is responsible for the reduction in the number of LEC progenitors in Prox $^{+/-}, \mathrm{Vegfr}^{+/-}$, and $\mathrm{VegfC}^{+/-}$embryos. We also show that this reduction is even more severe in Prox $1^{+/-}$;Vegfr $3^{+/-}$and Prox $1^{+/}$; Vegf $\mathrm{C}^{+/-}$embryos. We propose that in the mammalian embryo, this feedback loop is the main regulator of the number of LEC progenitors produced in the CV and ultimately the number of budding LECs that will participate in the formation of the mammalian lymphatic vasculature.

\section{Results}

\section{Vegfr3 is a dosage-dependent target of Prox1}

Because the number of LEC progenitors on the CV and the number of LECs outside the vein are reduced in Prox $1^{+/-}$ embryos (Srinivasan and Oliver 2011), we hypothesized that, in LEC progenitors, Proxl regulates at least some of its target genes in a dosage-sensitive manner and that the reduced levels of expression of these targets results in fewer LECs.

To identify some of those target genes, we first generated retroviral particles expressing Prox1, as previously reported (Srinivasan et al. 2010). We infected the mouse EC line $\mathrm{H}_{5} \mathrm{~V}$ (Garlanda et al. 1994) with the particles and then selected from the stably integrated viral genome individual clones expressing Prox1. We reasoned that the clones would have variable numbers of retroviral integration events, resulting in a variable amount of Prox1 expression. Following RNA isolation from these clones, we quantified the amount of Prox1 expression by using real-time PCR. As expected, the clones had a wide range of Prox1 expression levels (Fig. 1A). Similar variability in expression levels was also observed at the protein level using Western blot analysis (Fig. 1B).

Podoplanin is not expressed in venous Prox $1^{+}$LEC progenitors; instead, its expression is turned on once the cells bud from the vein as differentiating LECs at around E11.5 (Yang et al. 2012). Thus, we decided to identify the genes whose expression is regulated by Proxl in a dosagedependent manner prior to the activation of podoplanin expression. As expected and consistent with previous reports that used a similar strategy (Hong et al. 2002; Srinivasan et al. 2010), the infected $\mathrm{H}_{5} \mathrm{~V}$ cells expressed podoplanin but only in clones expressing the highest amounts of Prox1 (Supplemental Fig. 1). Next, we used a targeted approach and quantified the expression levels of various BEC- and LEC-specific genes (Foxc2, Integrin $\alpha$ 9, Coup-TFII, Reelin, Tie2, Nrp1, Nrp2, PECAM1, VECadherin, Lyve1, and Tie2) (Supplemental Fig. 1) in the different clones. Among those, the only gene whose expression level showed a tight correlation with that of Prox1 was Vegfr3 (Fig. 1A). This correlation with Vegfr3 is also seen at the protein level (Fig. 1B).

Because of the identified role of Vegfr3/Vegfc in early lymphangiogenesis and the compelling in vitro data suggesting that Vegfr3 is regulated by Prox1, we decided to validate this regulation further. To determine whether, in this context, Prox1 is a direct regulator of Vegfr3, we 

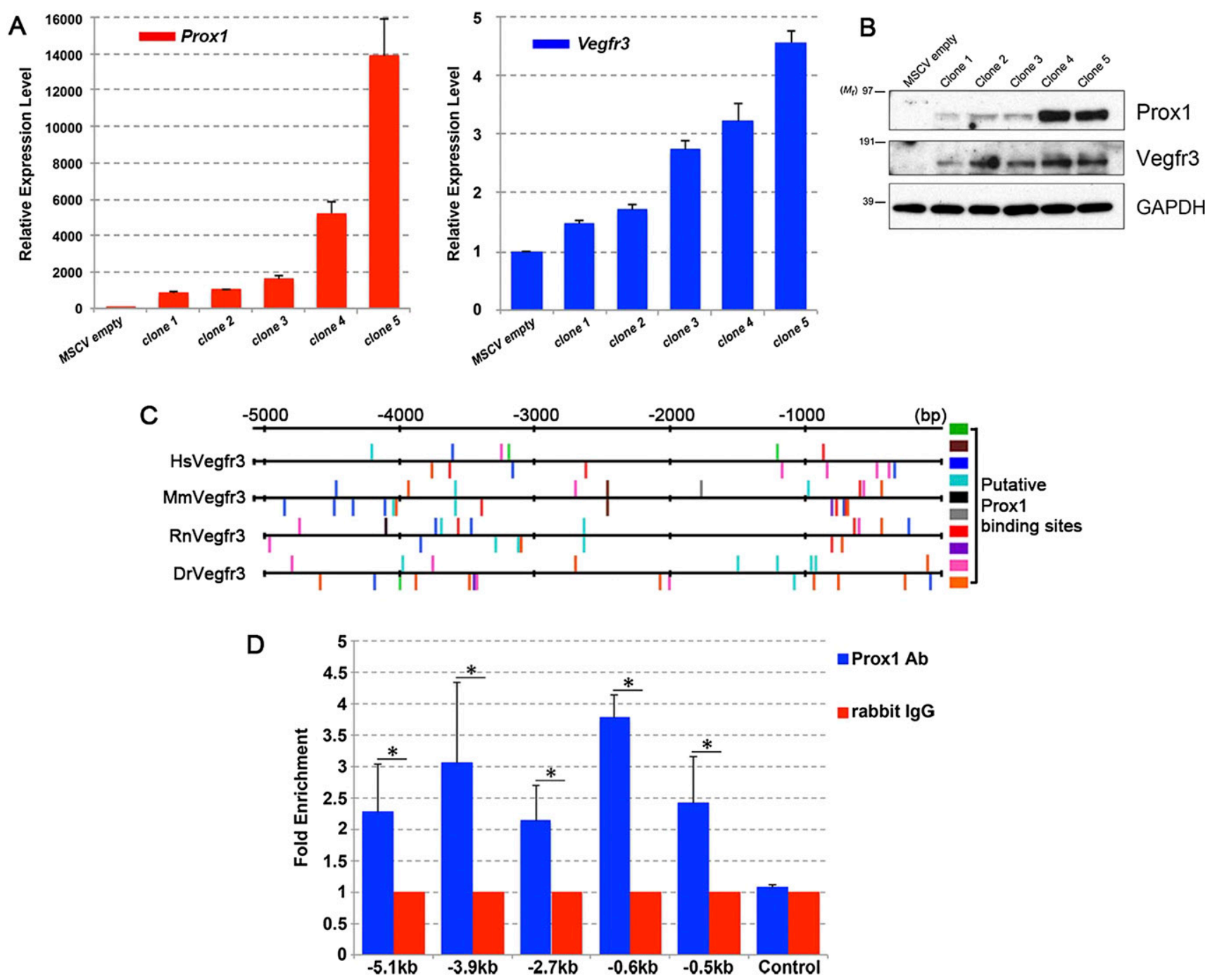

Figure 1. Vegfr3 is a dosage-dependent target of Prox1. (A) $\mathrm{H}_{5} \mathrm{~V}$ cells were infected with Proxl-expressing retroviruses. Individual clones were picked following positive selection with antibiotics. RNA extracted from the clones was analyzed by real-time PCR for the expression of Prox1 (left graph) and Vegfr3 (right graph). (B) Protein levels of Vegfr3 appear to correlate directly with those of Prox1. (C) DNA regions located $5 \mathrm{~kb}$ upstream of exon 1 of human $(\mathrm{Hs})$, mouse $(\mathrm{Mm})$, rat $(\mathrm{Rn})$, and zebrafish (Dr) Vegfr3 were analyzed for putative Proxl-binding sites by TRANSFAC bioinformatics software. Upward bars indicate the sites in the sense orientation, and downward bars indicate those in the antisense orientation. Colored boxes identify the different Prox1 recognition sites (see Supplemental Table 1). $(D)$ ChIP was carried out on mouse LECs collected by flow cytometry. A rabbit polyclonal antibody against Proxl or control IgG was used to pull down the DNA fragments. Real-time PCR was carried out using primers specific for the various regions along the 5-kb DNA element of mouse Vegfr3. Substantial Proxl binding was observed at the indicated sites. These data are from three independent experiments. $\left({ }^{\star}\right) P<0.05$.

performed a computational analysis to identify putative Prox1-binding sites. It was previously reported that a $3.6-\mathrm{kb}$ DNA fragment located upstream of the mouse Vegfr3 translational initiation site is sufficient to recapitulate its endogenous expression pattern (Iljin et al. 2001), and Proxl was also shown to activate luciferase reporters containing fragments of this regulatory element (Flister et al. 2010). Accordingly, we used the TRANSFAC bioinformatic software (Matys et al. 2006) to compare a 5-kb genomic region encompassing that DNA fragment across humans, mice, rats, and zebrafish. This software considers 12 different recognition sequences as putative Prox1 DNA- binding sites (Supplemental Table 1). Ten of the sites were identified within the different Vegfr3 regulatory regions of different species (Fig. 1C). To validate this initial analysis, we next sorted LECs from E14.5 mouse embryos and performed chromatin immunoprecipitation (ChIP) using an antibody specific for Proxl followed by real-time PCR to identify various fragments within the region. Five of the seven binding sites (located $5.1 \mathrm{~kb}, 3.9 \mathrm{~kb}, 2.7 \mathrm{~kb}, 0.6 \mathrm{~kb}$, and $0.5 \mathrm{~kb}$ upstream of the ORF of mouse Vegfr3) that we tested showed substantial enrichment of Proxl binding when compared with their IgG control and an independent region devoid of putative Prox1-binding sites (Fig. 1D). In 
conclusion, from this initial analysis, we identified Vegfr3 as a gene that is directly regulated by Proxl in a dosagesensitive manner.

\section{Lymphatic vasculature is defective in Prox $1^{+/ G F P C r e}$; Vegfr3 ${ }^{+/ L a c Z}$ embryos}

Prox $^{+/-}$mice develop edema embryonically, and nearly $70 \%$ die soon after birth (Srinivasan et al. 2010). If Vegfr3 is a dosage-dependent target of Prox 1 , then further reducing Vegfr3 levels would most likely aggravate the phenotype of Prox $1^{+/ G F P C r e}$ (Prox1 heterozygous) embryos. To better understand the functional significance of this regulation, we crossed $V e g f r 3^{+/ L a c Z}$ mice (Dumont et al. 1998) with Prox $1^{+/ G F P C r e}$ mice (Srinivasan et al. $2010)$ to generate Prox $1^{+/ G F P C r e}$;Vegfr $3^{+/ L a c Z}$ double-heterozygous embryos. Genotyping of nearly 300 live pups at the time of weaning identified no double-heterozygous animals, indicating that those animals died in utero or shortly after birth. To determine their cause of death, we collected E13.5 and E15.5 embryos. As described previously, Vegfr3 ${ }^{+/ L a c Z}$ embryos are normal (Fig. 2A), and, at those stages, most of the Prox $1^{+/ G F P C r e}$ embryos exhibit edema (Fig. 2B), and some display blood-filled lymphatics (data not shown). In the case of Prox $1^{+/ G F P C r e} ;$ Vegfr3 ${ }^{+/ L a c Z}$ embryos, the severity of the phenotype was variable:
Most of them exhibited severe edema and an accumulation of blood in different body regions (Fig. 2C), others showed a phenotype that is characteristic of blood-filled dermal lymphatics (Supplemental Fig. 2C), and some were almost devoid of lymphatic vessels in the skin (Supplemental Fig. 2D)

\section{The number of LEC progenitors and differentiating LECs is severely reduced in Prox $1^{+/ G F P C r e} ;$ Vegfr $3^{+/ L a c Z}$ embryos}

To further evaluate the lymphatic phenotype of Prox $1^{+/ \text {GFPCre }}$;Vegfr $3^{+/ L a c Z}$ embryos and determine whether the cause of their severe phenotype is a reduction in the number of LEC progenitors even greater than that seen in Prox1 heterozygous embryos (Srinivasan and Oliver 2011), we performed a detailed analysis at three key developmental time points. E11.5 and E13.5 Prox ${ }^{+/ G F P C r e}$; Vegfr ${ }^{+/ L a c Z}$ embryos were sectioned and immunostained for Prox1, podoplanin, and PECAM1. The same antibodies were used to immunostain the skin of E15.5 embryos. In E11.5 Prox $1^{+/ G F P C r e} ;$ Vegfr3 ${ }^{+/ L a c Z}$ embryos, the number of LEC progenitors in the CV and differentiating LECs outside the vein was reduced even more drastically than in Prox $1^{+/ G F P C r e}$ embryos (Fig. 2D-F). In addition, the level of podoplanin expression was down-
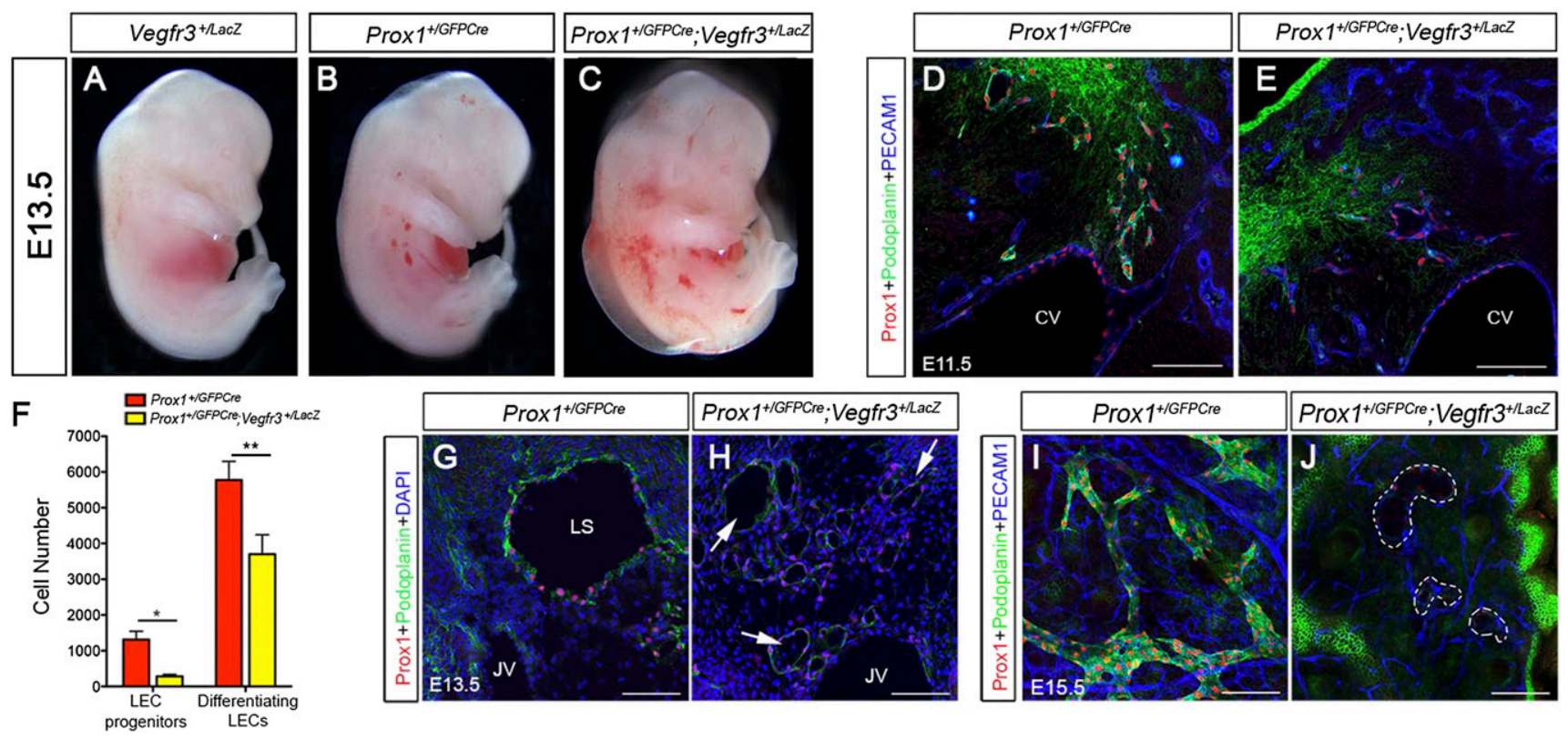

Figure 2. LEC progenitors and LECs are reduced in Prox $1^{+/ G F P C r e} ; \operatorname{Vegfr} 3^{+/ L a c Z}$ embryos. Vegfr $3^{+/ L a c Z}$ mice were bred with Prox $1^{+/ G F P C r e}$ to generate Prox $1^{+/ G F P C r e}$;Vegfr $3^{+/ L a c Z}$ double-heterozygous embryos. (A-C) At E13.5 Vegfr ${ }^{+/ L a c Z}$ embryos were phenotypically normal $(A)$, Prox $1^{+/ G F P C r e}$ embryos had mild edema $(B)$, and severe edema and regions of hemorrhagic accumulation were observed in most Prox $^{+/ G F P C r e} ;$ Vegfr3 ${ }^{+/ L a c Z}$ embryos $(C)$. Prox $1^{+/ G F P C r e}$ and Prox $1^{+/ G F P C r e} ;$ Vegfr3 ${ }^{+/ L a c Z}$ embryos were collected at E11.5 (D-F), E13.5 (G,H), or E15.5 $(I, I)$ and analyzed by immunohistochemistry for the LEC markers Proxl and podoplanin together with the pan-EC marker PECAM1. $(D, E, G, H)$ Transverse sections, with the neural tube and heart at the right and left, respectively, of the figures. $(I, J)$ Whole mounts on the peripheral skin. $(D, E)$ Compared with Prox $1^{+/ G F P C r e}$ embryos, the expression of Proxl and podoplanin is reduced in Prox $1^{+/ G F P C r e}$; Vegfr $3^{+/ L a c Z}$ littermates at E11.5. (F) Furthermore, the number of Prox $1^{+}$LECs is reduced in Prox $1^{+/ G F P C r e}$; Vegfr $3^{+/ L a c Z}$ embryos at E11.5 $\left(n=3\right.$ for each genotype). At E13.5, while a clear lymph sac (LS) was seen in Prox $1^{+/ G F P C r e}$ embryos $(G)$, scattered and mispatterned bloodfilled structures were seen in Prox $1^{+/ G F P C r e} ;$ Vegfr $3^{+/ L a c Z}$ embryos $\left(H_{;}\right.$arrows). At E15.5, lymphatic vessels are seen in Prox $1^{+/ G F P C r e}$ embryonic skin $(I)$; however, in Prox $1^{+/ \text {GFPCre}}$;Vegfr $3^{+/ L a c Z}$ embryos, the few Prox ${ }^{+}$structures (dashed lines) failed to express podoplanin $(J)$. $P$-values are as follows: ${\left({ }^{\star} \star\right.}^{\star}) P=0.0068 ;\left(^{\star}\right) P=0.0128$. Bars, $100 \mu \mathrm{m}$. 
regulated in the few scattered Prox $1^{+}$ECs seen outside of the CV (Fig. 2D,E). At E13.5, relatively normal-looking lymph sacs were seen in Prox $1^{+/ G F P C r e}$ embryos (Fig. 2G); in contrast, several scattered blood-containing enlarged structures were seen in Prox $1^{+/ G F P C r e} ; \mathrm{Vegfr}^{+/ L a c Z}$ embryos at this stage (Fig. 2H, arrows). The levels of Proxl and podoplanin expression were also drastically reduced at E13.5 in these double-heterozygous embryos (Fig. 2H). At E15.5, mostly normal-looking lymphatic vessels were seen in the skin of Proxl heterozygous embryos (Fig. 2I; Supplemental Fig. 2B,F). Instead, as mentioned above, many Prox $1^{+/ G F P C r e}$;Vegfr $3^{+/ L a c Z}$ embryos exhibited bloodfilled dermal lymphatics (Supplemental Fig. 2C), and, consistent with the X-gal staining data (Supplemental Fig. 2D), some Prox $1^{+/ G F P C r e} ;$ Vegfri ${ }^{+/ L a c Z}$ embryos were almost devoid of lymphatic vessels in the skin, as shown by the lack of Proxl and Vegfr3 staining (Supplemental Fig. 2H). The few Prox $1^{+}$vessels detected in those embryos were devoid of podoplanin expression (Fig. 2J, dashed lines).

\section{LEC progenitor identity is lost in Prox $1^{+/ G F P C r e}$; Vegfr $3^{+/ L a c Z}$ embryos}

The reduced number of LECs in Prox $1^{+/ G F P C r e}$; Vegfri $3^{+/ L a c Z}$ embryos could be caused by a reduction in cell proliferation, an increase in apoptosis, or the loss of LEC identity. Prox1 heterozygous embryos that have fewer LECs do not exhibit altered cell proliferation or apoptosis (Srinivasan and Oliver 2011). Instead, they fail to maintain LEC fate. This led us to believe that something similar could happen in Prox $1^{+/ \text {GFPCre }} ;$ Vegfr3 $3^{+/ L a c Z}$ embryos; however, proliferation and apoptosis assays did not reveal obvious alterations in these embryos at E11.5 (data not shown).

In the case of Prox1 heterozygous embryos, we previously used a lineage-tracing approach to follow the fate of LEC progenitors. To that end, we crossed the Prox $1^{+/ G F P C r e}$ mice with $R 26^{+/ Y F P}$ mice in which $R 26$ was ubiquitously expressed, and an YFP reporter cassette was targeted into the locus downstream from a transcription stop cassette that was flanked by LoxP sites (Soriano 1999; Jeong et al. 2004). In Prox $1^{+/ G F P C r e}$ animals, Cre recombinase is expressed where Proxl is expressed (Srinivasan et al. 2010). Cre-mediated deletion of the stop cassette in $R 26^{+/ Y F P}$ mice activates the expression of YFP in all Proxl-expressing cells and their descendants irrespective of the subsequent presence or absence of the expression of Proxl or Cre. Using this approach, we previously identified numerous Prox $1^{-}$; YFP ${ }^{+}$ECs on the CV of E13.5 Prox1 heterozygous embryos (Srinivasan and Oliver 2011). This finding conclusively argued that the Prox $1^{+}$LEC progenitors had reverted to their original venous EC fate by losing Prox1 expression.

To determine whether Vegfr3 is also involved in maintaining LEC fate, we performed a similar lineage-tracing experiment in the Vegfr $3^{+/ L a c Z}$ background. We used the $R 26^{\mathrm{mT} / m G}$ mice (Muzumdar et al. 2007) that express a fluorescent membrane-tagged GFP that fluoresces stronger than the YFP of $R 26^{+/ Y F P}$ mice. Numerous $\mathrm{GFP}^{+}$; Prox $1^{-}$ cells were detected in the CV of E10.5 Prox $1^{+/ G F P C r e}$;
$R 26^{m T / m G}$ embryos (Fig. 3A-C, white dotted line). However, the number of $\mathrm{GFP}^{+}$;Prox1 ${ }^{-}$ECs detected was greater (nonsignificant but with a trend $P$-value $=0.065)$ in Prox $1^{+/ G F P C r e}$; $\mathrm{Vegfr}^{+/ L a c Z} ;{ }^{\prime} 26^{\mathrm{mT} / \mathrm{mG}}$ littermates (Fig. 3D-F [white dotted line], G). Thus, Vegfr3 is likely involved in maintaining LEC progenitor fate.

\section{Vegfr3 regulates Prox1 expression in LEC progenitors and LECs}

One possible mechanism by which Vegfr3 maintains LEC fate could be by regulating Proxl, a known regulator of LEC progenitor identity. To evaluate this possibility, we isolated E11.5 LEC progenitors (inside the CV) and differentiating LECs (outside the CV) using a laser capture microdissection approach from wild-type, Prox1 heterozygous, and Vegfr3 heterozygous embryos. Prox1 and Vegfr3 mRNA levels were compared in these different cell populations by quantitative PCR (qPCR). In wild-type embryos, Prox1 and Vegfr3 levels were higher in differentiating LECs than in progenitors (Fig. 4). As expected, Vegfr3 expression in LEC progenitors was reduced in Prox1 heterozygous embryos (Fig. 4B). In addition, we found that Prox1 expression was also reduced in Vegfr3 heterozygotes (Fig. 4A). Interestingly, the reduction in the expression of these two genes was in not only LEC progenitors but also differentiating LECs outside of the CV (Fig. 4).

Due to the severely reduced numbers of LECs, we were unable to perform a similar laser capture and qPCR analysis in Prox $1^{+/ G F P C r e} ;$ Vegfr3 $^{+/ L a c Z}$ embryos. However, as reported above, we used image analysis software to quantify the fluorescent intensity of Vegfr3 and Prox1 as a measure of their expression levels in semiquantitative immunohistochemical analysis. As before, we grouped the cells as progenitors (on the vein) or differentiating LECs (outside). Consistent with the qPCR data, Vegfr3 expression was reduced in LEC progenitors and differentiating LECs in E11.5 Prox1/GFPCre embryos (Fig. 5I,J). Proxl expression was also reduced in both populations in Vegfr $3^{+/ L a c Z}$ embryos (Fig. 5I,J). Moreover, Vegfr3 and Prox1 levels were even more reduced in Prox $1^{+/ G F P C r e}$; Vegfr $3^{+/ L a c Z}$ (double-heterozygous) embryos than in their Prox $1^{+/ G F P C r e}$ or Vegfr3 ${ }^{+/ L a c Z}$ littermates (Fig. 5I,J). Expression of the pan-endothelial marker PECAM1 was not significantly different between the samples, although, as expected, its expression was higher in progenitors relative to differentiated LECs (Fig. 5I,J). These in vivo results strongly support the presence of a positive feedback loop between Prox1 and Vegfr3 in LECs.

Blood flow was shown to down-regulate the expression of LEC-specific genes, particularly that of Prox1 (Chen et al. 2012). To evaluate whether venous blood flow could be responsible for the observed down-regulation of Prox 1 levels in Vegfr3 heterozygous embryos, we used an in vitro approach in which Prox1 or Vegfr3 activity was knocked down using specific siRNAs in hLECs. By using Alexa-Fluor-564-conjugated siRNA and performing flow cytometry, we determined that the siRNA transfection efficiency was $\sim 85 \%$ (data not shown). Quantitative real- 

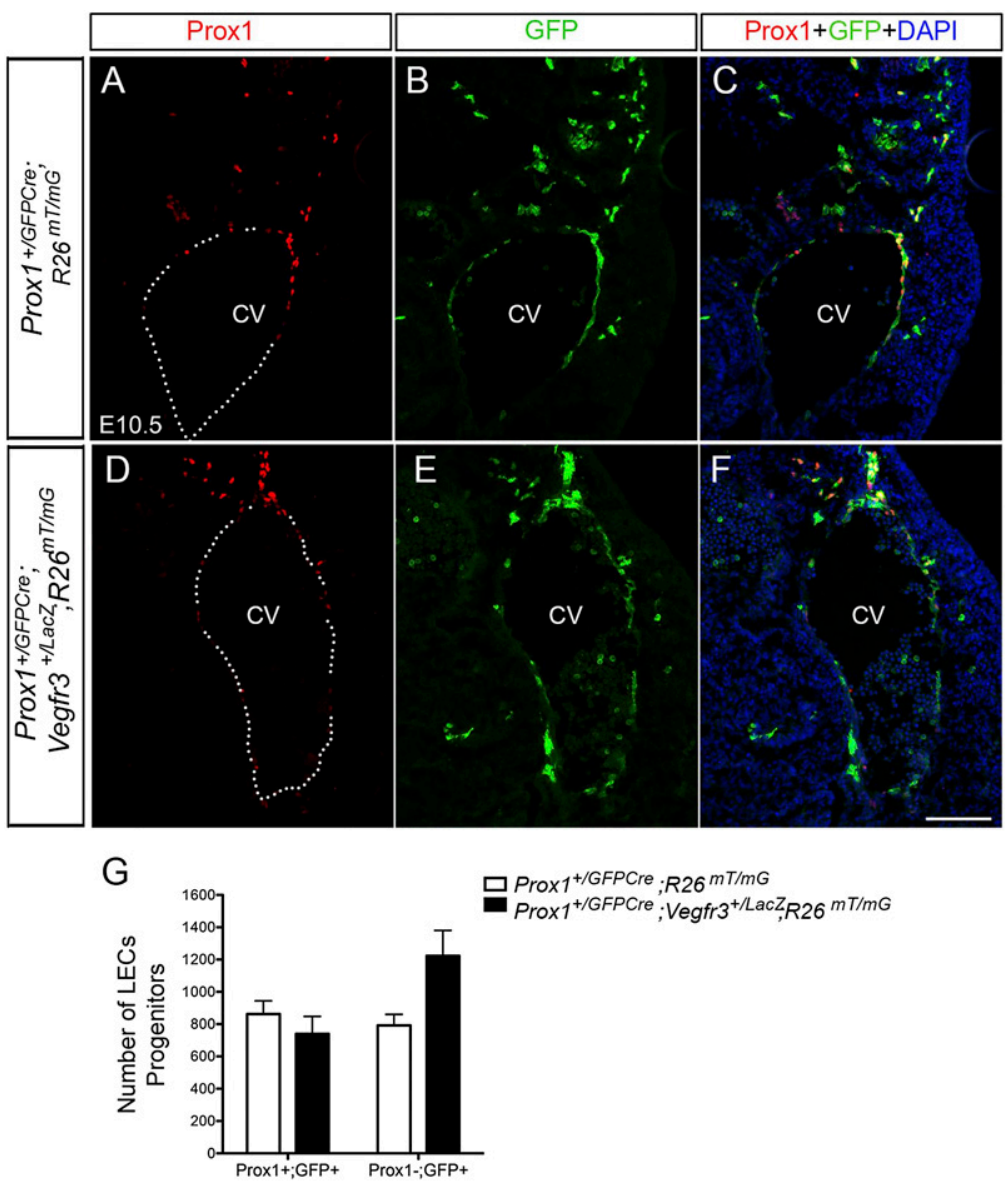

Figure 3. Prox $1^{+/ \text {GFPCre }}$; Vegfr3 $3^{+/ L a c Z}$ embryos fail to maintain Prox1 expression in LEC progenitors. Prox $1^{+/ G F P C r e}$ mice were bred with Vegfr $3^{+/ L a c Z}$; $R 26^{\mathrm{mT} / \mathrm{mG}}$ mice, and the resulting E10.5 Prox $1^{+/ G F P C r e}$; $R 26^{\mathrm{mT} / \mathrm{mG}}$ and Prox $1^{+/ G F P C r e} ;$ Vegfr $3^{+/ L a c Z} ; R 26^{\mathrm{mT} / \mathrm{mG}}$ embryos were analyzed by immunohistochemistry for Prox 1 and GFP. Upon Cre-mediated activation, the $R 26^{\mathrm{mT/mG}}$ reporter expresses a membranetagged GFP that allows the visualization of the cell surface. $(A-C)$ In Prox $1^{+/ G F P C r e} ; R 26^{m T / m G}$ embryos, numerous Prox $1^{+}$cells were seen on the CV. All of these cells and a few Prox $1^{-}$cells on the CV were $\mathrm{GFP}^{+}$ (white dotted line). $(D-F)$ In contrast, in Prox $1^{+/ G F P C r e}$; $\mathrm{Vegfr}^{+/ L a c Z} ; \mathrm{R}^{2} 6^{\mathrm{mT} / \mathrm{mG}}$ embryos, fewer Prox $1^{+}$cells were seen on the $\mathrm{CV}$, although most of these cells were $\mathrm{GFP}^{+}$(white dotted line). Bars, $100 \mu \mathrm{m}$. $(G)$ For cell counting, the number of $\mathrm{GFP}^{+}$Prox $1^{-} \mathrm{DAPI}^{+}$or $\mathrm{GFP}^{+}$Prox $1^{+} \mathrm{DAPI}^{+}$cells were quantitated in stained sections ( $n=3$ embryos for each genotype). Cell counting showed that the number of Prox $1^{-} \mathrm{GFP}^{+}$ LEC progenitors $(P$-value $=0.065)$ was higher in double heterozygous, indicating that the Vegfr3Proxl interaction is required to maintain LEC fate. time PCR analysis demonstrated that, as expected and in agreement with previous results (Mishima et al. 2007; Lee et al. 2009; Pan et al. 2009), Vegfr3 levels were downregulated when Prox1 is knocked down (Fig. 6A). Likewise, Prox $1 \mathrm{mRNA}$ levels decreased $\sim 40 \%$ after siVegfr3 transfection in hLECs (Fig. 6A). At the protein level, endogenous Proxl protein was detected in the nuclei of hLECs transfected with control siRNA, whereas Prox1 protein was decreased or not detected in LECs transfected with siProx1 or siVegfr3 (Fig. 6B, arrowheads) These results argue that the feedback loop regulation between Prox1 and Vegfr3 is at the RNA and protein levels, that it is most likely independent of blood flow, and that it takes place in LEC progenitors and differentiating LECs.

\section{Vegfc signaling helps maintain LEC progenitor identity}

In $V e g f c^{-/-}$embryos, LEC progenitors remain inside the $\mathrm{CV}$; thus, Vegfc activity is required for these cells to bud from the vein (Karkkainen et al. 2004). The data presented above showed that a Prox1-Vegfr3 feedback loop in LEC progenitors helps maintain Proxl expression. Accordingly, as Vegfc activates Vegfr3 signaling, the number of venous LEC progenitors in Vegfc ${ }^{-/}$embryos should be lower than in their control littermates. To test this possibility, we immunostained E10.5 $\mathrm{Vegfc}^{+/-}$and $\mathrm{Vegfc^{-/- }}$ embryos (Karkkainen et al. 2004) against the LEC markers Proxl and Lyve1. At this stage, in Vegfc heterozygous embryos, Prox $1^{+}$Lyve $1^{+}$LEC progenitors lined the anterior $\mathrm{CV}$, and Prox $1^{+}$LECs cells were budding from the vein (Supplemental Fig. 3A). However, fewer Prox $1^{+}$ LEC progenitors remained inside the $\mathrm{CV}$ of $V e g f \mathrm{C}^{-/-}$ embryos (Supplemental Fig. 3B,C). Furthermore, compared with wild-type littermates, the number of LEC progenitors and LECs was reduced in E11.5 Prox $1^{+/ G F P C r e}$ and $\mathrm{VegfC}^{+/-}$embryos, as previously described (Fig. 7A-C; Srinivasan and Oliver 2011; Hagerling et al. 2013). These numbers were more dramatically reduced at E11.5 in Prox $1^{+/ G F P C r e} ;$ Vegfc $^{+/-}$embryos when compared with Prox $1^{+/ G F P C r e}$ or $V e g f \mathrm{c}^{+/-}$littermates, a result providing further support to the proposed regulatory interaction between Prox1 and Vegfc/Vegfr3 signaling (Fig. 7D,E). No surviving Prox $1^{+/ G F P C r e} ;$ Vegfc ${ }^{+/-}$pups were found from these crosses. Finally, to determine whether the reduction in LEC numbers seen in Prox1,Vegfc doubleheterozygous embryos is due to the reversal of LEC progenitor fate into venous ECs, we generated Prox $1^{+/ G F P C r e}$; $\mathrm{Vegfc}^{+/-} ; R 26^{\mathrm{mT} / \mathrm{mG}}$ embryos as described previously. As expected, several $\mathrm{GFP}^{+}$Prox1 ${ }^{-} \mathrm{DAPI}^{+}$cells were seen on the veins of Prox $1^{+/ G F P C r e} ; R 26^{m T / m G}$ embryos (Supplemental Fig. 4A, white dotted line); however, these numbers were higher in Prox $1^{+/ G F P C r e} ; \operatorname{Vegfc}^{+/-} ; R_{2} 6^{\mathrm{mT} / \mathrm{mG}}$ embryos (Supplemental Fig. 4D, white dotted line), in- 
A

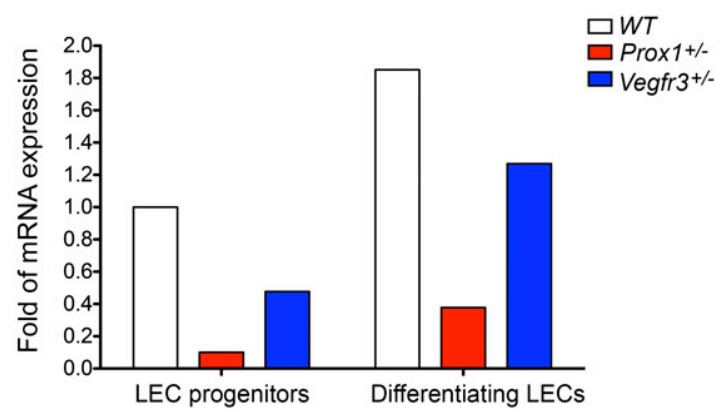

B

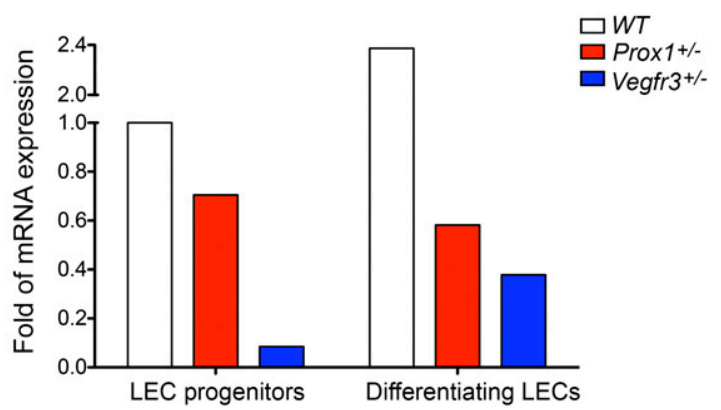

Figure 4. Vegfr3 regulates Prox1 expression in LEC progenitors and differentiating LECs. Wild-type (WT) [Tg(Prox1-tdTomato)], Prox ${ }^{+/-}$ $\left[\right.$ Tg(Prox1-tdTomato);Prox $\left.1^{+/ L a c Z}\right]$, and Vegfr3 ${ }^{+/-}\left[\right.$Tg(Prox1-tdTomato); Vegfr $\left.3^{+/ L a c Z}\right]$ embryos were collected at E11.5 (one embryo per genotype). Using laser capture microdissection, LEC progenitors (inside the CV) and differentiating LECs (outside the CV) were collected separately, and the levels of Prox1 $(A)$ and Vegfr3 $(B)$ were analyzed by quantitative real-time PCR. mRNA levels are shown as fold of increase and were normalized to PECAM1 levels. These qPCR results were generated from a single laser capture experiment using pooled mRNA extracted from cells captured from 10- $\mu \mathrm{m}$ sections obtained from the entire embryo for each genotype.

dicating that Vegfc also cooperates with Prox1 in the maintenance of LECs progenitors.

Although these results provide further support for a Prox1-Vegfr3 feedback loop in LECs, it could still be argued that the observed results are the consequence of the loss of LEC fate and therefore of the expression of LEC-specific genes upon Prox1 or Vegfr3 inactivation. To address this possibility, we cultured hLECs in the presence of Vegfc and found that Vegfr3 and Prox1 expression was up-regulated 3.0-fold and 2.8-fold above baseline, respectively (Supplemental Fig. 5). These quantifications were done with internal controls to normalize for cell numbers (data not shown).

Together, these results argue that Prox $1^{+}$LEC progenitors require Vegfr3 to maintain their identity and bud from the $\mathrm{CV}$ and that this regulation is mediated through the activation of Vegfr3 by Vegfc. Alterations in VegfcVegfr3 signaling leads to the loss of Prox1 expression in LEC progenitors and their reversal to venous EC fate.

\section{Discussion}

We showed previously that Prox1 heterozygous embryos exhibit a reduction in the number of LEC progenitors and, consequently, LECs because of a defect in maintaining Prox1 expression (Srinivasan and Oliver 2011). To better characterize the molecular steps leading to the formation and maintenance of LEC progenitors, we identified direct in vivo downstream targets of Proxl that are regulated in a dosage-dependent manner. Using a combination of in vitro and in vivo approaches, we identified Vegfr3 as a dosage-dependent target of Proxl and demonstrated that, in turn, Vegfc-Vegfr3 signaling is necessary to maintain Prox 1 in LECs. Consistent with these data, Vegfr3 $^{+/-}$and $V e g \mathrm{fC}^{+/-}$embryos have reduced numbers of LEC progenitors and LECs (Hagerling et al. 2013). Our lineagetracing experiments further revealed that this reduction is due to the reversal of LEC progenitor fate into venous ECs. We conclude that a feedback loop between Prox1 and Vegfr3 is important for maintaining LEC fate and therefore for regulating the number of LEC progenitors being specified in the CV and their subsequent budding to form the complete lymphatic vasculature.

Feedback loops that operate between transcription factors and signaling molecules are known to regulate the normal development of many tissues. Such feedback loops most likely play an important role in rapidly amplifying the molecular programs that control lineage differentiation. Based on the generated data, we propose a simple model to explain the functional significance of the newly identified Prox1-Vegfr3 feedback loop in lymphatic vascular development (Fig. 8). According to this model, Coup-TFII and Sox18 provide the initial "spark" for LEC specification by initiating the expression of Prox 1 in the CV at around E9.75. In turn, this expression of Prox1 will be necessary to maintain Vegfr3 expression in venous LEC progenitors. Vegfc, whose expression is stronger in the mesenchyme on the dorso-lateral side of the anterior CVs where LECs bud directly (Karkkainen et al. 2004), will trigger the Prox1-Vegfr3 feedback loop by stabilizing Prox 1 and therefore Vegfr3 expression on that side of the vein and will be responsible for the budding of those progenitors. The lack of Vegfr3 expression in ECs of the lymphovenous valves (Srinivasan and Oliver 2011) may explain why those cells remain inside the vein.

Reduction in Vegfr3-mediated signaling in Prox $1^{+/-}$, Prox $^{-/-}$, Vegfr3 $^{+/-}$, Vegfc $^{+/-}$, Vegfc $^{-1-}$ Prox $^{+/-}{ }^{-} \mathrm{Vegfc}^{+/-}$, and Prox ${ }^{+/-}$;Vegfr3 $3^{+/-}$embryos results in the silencing of Prox1 expression in some or all LEC progenitors and therefore results in the reduction in the number of LECs. It is worth pointing out that Vegfc-mediated signals could be modulated by multiple mechanisms. Mice that carry a deletion in the Vegfc-binding domain of Vegfr3 $\left(\right.$ Vegfr $\left.3^{L B D / L B D}\right)$ still retain their ability to form lymph sacs (Zhang et al. 2010). In this context, Neuropilin-2 (Nrp-2) could bind Vegfc and function as a coreceptor for Vegfr3 (Zhang et al. 2010). Vegfr ${ }^{L B D / L B D}$ embryos are nevertheless severely edematous due to reasons that remain unknown (Zhang et al. 2010). Based on our data, we predict that it is a defect in the Prox1-Vegfr3 feedback 

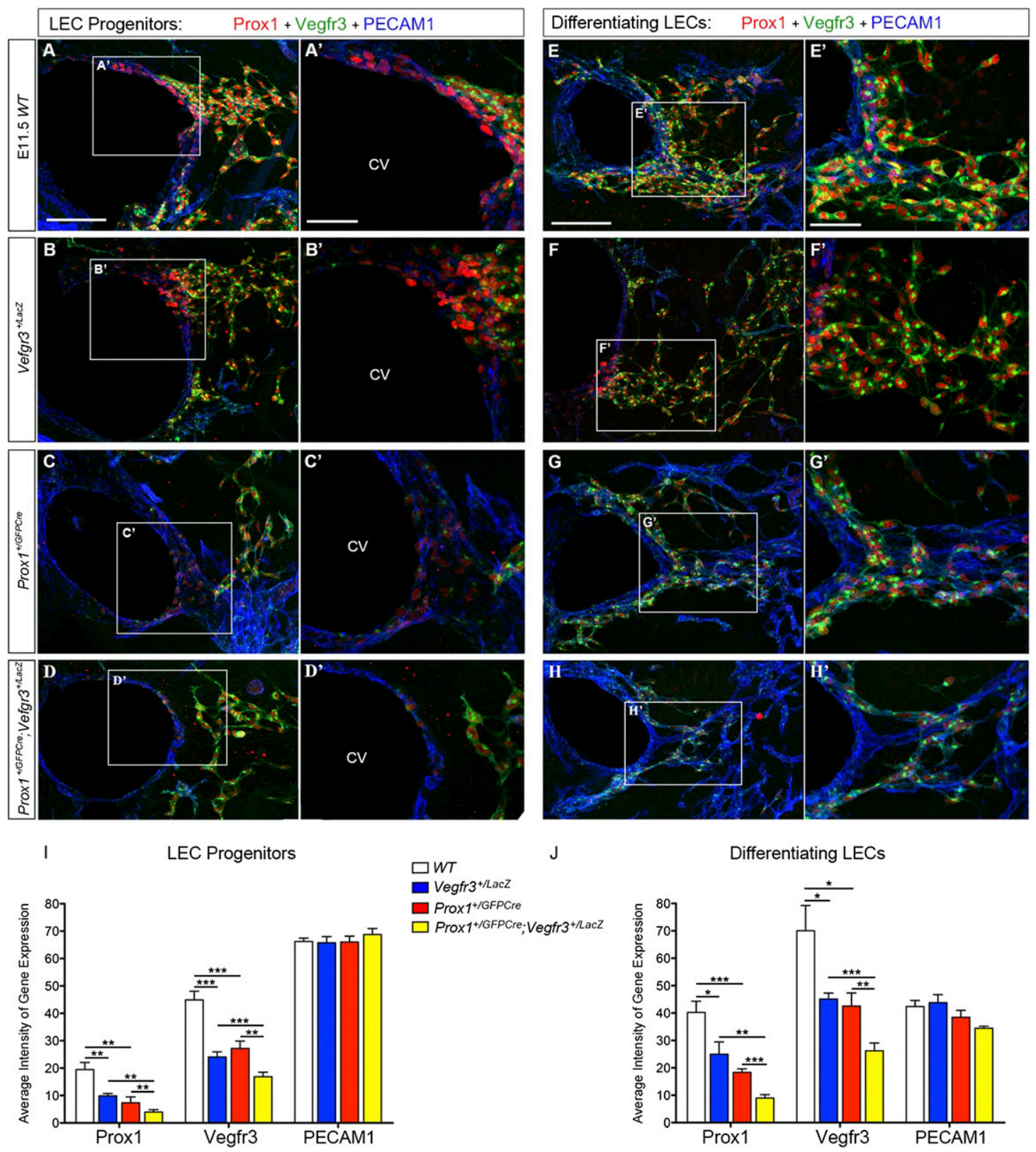

Figure 5. Prox 1 and Vegfr3 levels are reduced in Prox $1^{+/ G F P C r e} ;$ Vegfr $3^{+/ L a c Z}$ embryos. $\left(A-H^{\prime}\right)$ Immunohistochemistry for Prox 1 , Vegfr3, and PECAM1 was carried out in E11.5 wild-type (WT) $\left(A, A^{\prime}, E, E^{\prime}\right), \operatorname{Vegfr}^{+/ L a c Z}\left(B, B^{\prime}, F, F^{\prime}\right)$, Prox $1^{+/ G F P C r e}\left(C, C^{\prime}, G, G^{\prime}\right)$, and Prox $1^{+/ G F P C r e}$; $\operatorname{Vegfr} 3^{+/ L a c Z}\left(D, D^{\prime}, H, H^{\prime}\right)$ embryos. The expression levels of Prox1, Vegfr3, and PECAM1 in venous LEC progenitors $\left(A-D^{\prime}\right)$ and differentiating LECs outside of the CV $\left(E-H^{\prime}\right)$ were quantified using the Slidebook image analysis software $(I, J)$. Proxl and Vegfr3 expression levels were significantly reduced in Prox $1^{+/ G F P C r e} ;$ Vegfr $3^{+/ L a c Z}$ embryos compared with their single heterozygous littermates. At least three embryos for each genotype were used for quantification. Bars: $A-H, 100 \mu \mathrm{m}$.

loop that leads to the reduction in the number of LEC progenitors and LECs in these embryos. The Prox1Vegfr3 feedback loop could also be modulated by CCBE1, a protein that proteolytically processes Vegfc (Jeltsch et al. 2014). Any of the aforementioned proteins could also affect the timing and number of specified LEC progenitors, and it could be possible that Proxl might also control the expression of some of them. In fact, our transfection assay showed that Prox1 up-regulates Nrp-2 expression in $\mathrm{H}_{5} \mathrm{~V}$ cells (Supplemental Fig. 1).
It has been proposed that Jagged1/Notch1 signaling is responsible for the down-regulation of Coup-TFII expression in a subset of venous ECs in the early CV such that LEC progenitors are not specified in that subpopulation (Murtomaki et al. 2013). At the same time, in neighboring venous EC cells with low or no Notch signaling, CoupTFII is up-regulated (Murtomaki et al. 2013). In these cells, Coup-TFII in turn inhibits Notch signaling but activates Prox1 (You et al. 2005; Srinivasan et al. 2010). This argument is in agreement with results from Murtomaki et al. 

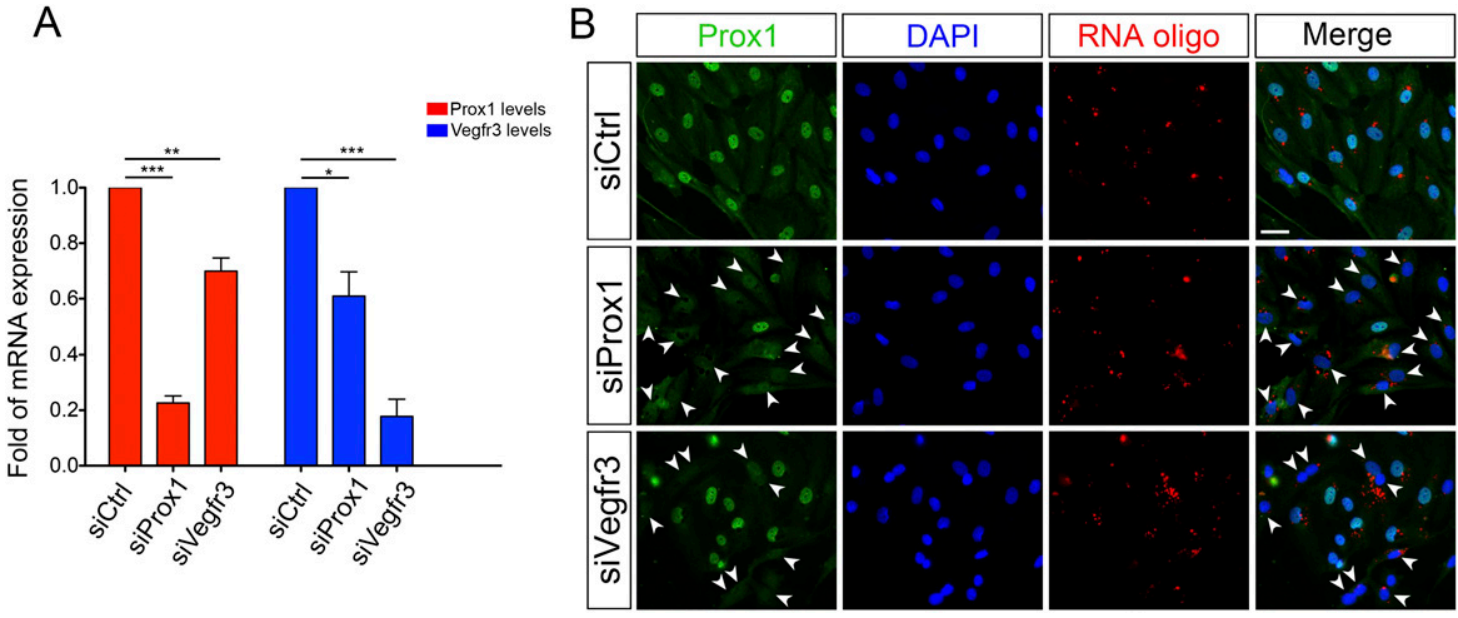

Figure 6. Feedback loop regulation between Proxl and Vegfr3 is at the RNA and protein levels. $(A)$ hLECs were transfected with siRNAs and cultured in conditioned medium. After $48 \mathrm{hm}$ mRNA was extracted, and qPCR was carried out to quantify Prox1 and Vegfr3 expression levels. siProxl down-regulates both Prox1 and Vegfr3 levels $(P<0.0001$ and $P=0.0108$, respectively $)$. Likewise, siVegfr3 down-regulates both Vegfr3 and Prox1 levels $(P=0.0003$ and $P=0.0051$, respectively). These data are the result of three independent experiments. $(B)$ hLECs transfected with siRNA were cultured and immunostained for Proxl. Prox 1 expression was downregulated in those cells that were successfully transfected with fluorescently labeled siRNAs directed against either Prox1 or Vegfr3 (arrowheads).

(2013) showing that Notch1 is capable of suppressing Prox1 expression (likely via repression of Coup-TFII) in early embryonic LECs and that deletion of one allele of Notch1 rescues Prox1 haploinsufficiency. In the context of our findings (see Fig. 8), it could be speculated that early on in the CV, some venous ECs are devoid of Notch signaling, or its threshold is below the one necessary to repress Coup-TFII. Therefore, in those venous ECs, CoupTFII together with Sox18 induce Proxl expression such that LEC specification takes place, and the Prox1/Vegfr3 feedback loop is initiated and maintained in LEC progenitors. Interestingly, we found that Notch1 levels were increased in LEC progenitors of Prox1 heterozygous embryos as well as in hLECs transfected with Proxl siRNA (data not shown), a result suggesting that there could also be cross-regulation between Notch signaling and Prox 1 in LECs such that, at those early stages, Prox 1 expression in LEC progenitors maintains Notch expression at low levels. Later on (after approximately E13.5) (see Fig. 8), for reasons that we still do not understand, the threshold of Notch signaling in venous ECs increases to a level sufficient to directly repress Coup-TFII and, as a consequence, shut off Proxl expression. At the same time, this increase in Notch signaling levels is probably also sufficient to inhibit Vegfr3 activity via its effectors, Heyl and Hey2 (Murtomaki et al. 2013). As a consequence (see Fig. 8), it is likely that the Prox1-Vegfr3 feedback loop will be disrupted and so will the generation of LEC progenitors in the CV at those later stages.

Another level of complexity is added by the fact that Coup-TFII and Proxl could interact to form a protein complex (Lee et al. 2009; Yamazaki et al. 2009; Srinivasan et al. 2010). We previously determined that the reduction in the number of Prox1-expressing LEC progenitors in Prox $1^{+/-}$embryos was the consequence of a decrease in the amount of the available Coup-TFII/Proxl protein complex (Srinivasan and Oliver 2011). This complex is known to activate Vegfr3 in LECs (Lee et al. 2009; Yamazaki et al. 2009). Coup-TFII also activates Nrp-2, although it is currently unknown whether this is via the Coup-TFI/ Proxl complex (Lin et al. 2010). Alternatively, it could then be argued that the Coup-TFI/Proxl protein complex might regulate the expression of additional LEC-specific genes such as Hey1/2, as recently reported (Aranguren et al. 2013), and these genes in turn inhibit Vegfr3 expression.

We found that the Prox1-Vegfr3 feedback loop is operational in not only LEC progenitors but also differentiating LECs at least until E13.5. How is this loop operating in functional lymphatics and in what context? Are there other players involved? It was previously shown that the expression of Prox1 and Vegfr3 is down-regulated in collecting lymphatic vessels during maturation (Norrmen et al. 2009). While the functional relevance of this downregulation is not yet clear, this down-regulation appears not to take place in Foxc2 $2^{-/-}$embryos that fail to undergo proper collecting vessel maturation (Norrmen et al. 2009). It is possible that a subtle interference with the Prox1-Vegfr3 feedback loop by Foxc2 results in a sudden and dramatic reduction in their expression levels and the subsequent maturation of the lymphatic vessel. A genetic interaction between Foxc2 and Vegfr3 has been reported (Petrova et al. 2004).

In summary, we propose that the Prox1-Vegfr3 feedback loop is a simple but necessary sensing mechanism required to maintain LEC fate and regulate the number of specified LEC progenitors and, subsequently, the number of budding LECs. Clearly, we only solved a small portion of a jigsaw puzzle, and future research with the advancement of appropriate technologies will help us put together the other pieces. 


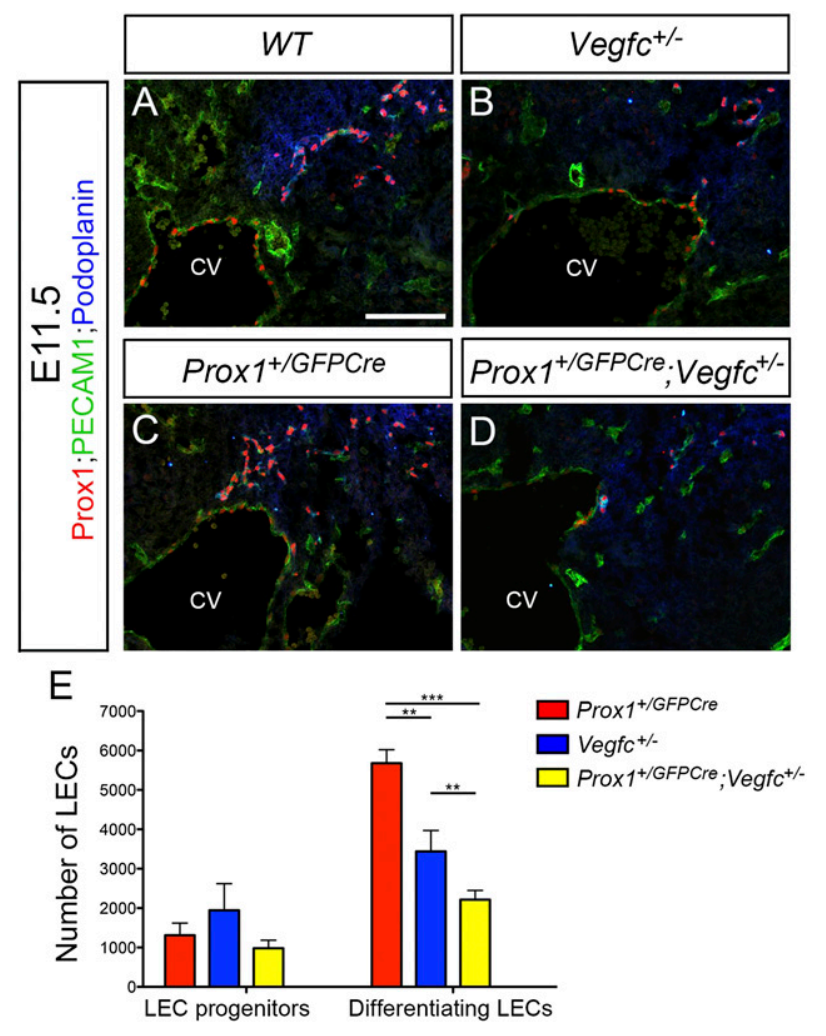

Figure 7. Prox1 and Vegfc genetically interact with each other to regulate the number of LEC progenitors and LECs. $(A-D)$ Prox $1^{+/ G F P C r e}$ and $V e g f c^{+/-}$mice were bred with each other, and embryos were collected at E11.5 and analyzed by immunohistochemistry for the LEC markers Prox 1 and podoplanin together with the pan-EC marker PECAM1. Compared with wild-type (WT) embryos $(A), \operatorname{Vegfc}^{+/-}(B)$ and Prox1 $1^{+/ G F P C r e}(C)$ embryos had fewer Prox $1^{+}$LEC progenitors and LECs. $(D)$ Prox $1^{+/ G F P C r e}$; $V e g f C^{+/}$embryos had even fewer LECs. (E) Quantification of the cell numbers revealed that the differences in differentiating LEC numbers are statistically significant $\left(\left[{ }^{\star \star \star}\right] P \leq 0.001 ; n=3\right.$ embryos for each genotype). Regarding LEC progenitors, there is no significant difference; however, there is a trend that shows that the number of LECs decreases in the double-heterozygous embryos $(P=0.0925)$. Bar, $100 \mu \mathrm{m}$.

\section{Materials and methods}

Mice

$R 26^{+/ Y F P}, R 26^{m T / m G}$, and $T g$ (Prox1-tdTomato) mice were obtained from the Jackson Laboratory (Jeong et al. 2004; Muzumdar et al. 2007; Truman et al. 2012). Vegfc ${ }^{+/-}, \operatorname{Prox}^{+/ \text {LacZ }}$, Prox $^{+/ \text {GFPCre }}$, and Vegfr3 $3^{+/ L a c Z}$ mice have been reported previously (Dumont et al. 1998; Wigle et al. 1999; Karkkainen et al. 2004; Srinivasan et al. 2010). All mouse experiments were approved by the International Animal Care and Use Committee (IACUC) at St. Jude Children's Research Hospital.

\section{Viral constructs and generation of viral particles}

Avitag-Prox1 was cloned into a two-promoter MSCV-fl-sv-Puro retroviral vector containing the LTR promoter and an SV40-PAC selection cassette. Viral particles pseudotyped with VSV-G and PEQ-PAM were generated by transient transfection in 293T cells. Briefly, 293T cells were plated at $2 \times 10^{6}$ cells per $100-\mathrm{mm}-$ diameter tissue culture dish and transfected with the retroviral vector (empty or containing avitag-Prox1) by using FuGENE 6 (Roche Applied Science). At $12 \mathrm{~h}$ post-transfection, the medium was replaced with fresh DMEM containing 10\% FBS, and cells were grown for an additional $24 \mathrm{~h}$. The conditioned medium containing recombinant retroviruses was collected and filtered through polysulfonic filters (pore size, $0.45 \mu \mathrm{m}$; Corning).

\section{Viral transduction and selection of $\mathrm{H}_{5} \mathrm{~V}$ clones expressing Prox1}

For retroviral infections, $\mathrm{H}_{5} \mathrm{~V}$ cells were transduced with viral particles for $24 \mathrm{~h}$. Samples of retrovirus supernatants were applied to $\mathrm{H}_{5} \mathrm{~V}$ cells, which had been plated $18 \mathrm{~h}$ prior to infection at a density of $10^{6}$ cells per tissue culture dish (100-mm diameter). Polybrene (Sigma) was added to a final concentration of $8 \mathrm{mg} / \mathrm{mL}$, and the supernatants were incubated with the cells for $12 \mathrm{~h}$. After infection, cells were placed in fresh growth medium and maintained in culture as usual. Selection with $1.5 \mathrm{mg}$ of puromycin per milliliter was initiated $12 \mathrm{~h}$ after infection. About $7 \mathrm{~d}$ after selection, $1 \times 10^{4}$ cells were seeded into each tissue culture dish (100-mm diameter) to form individual clones. The individual clones picked from microplates of the retrovirus-infected cells were transferred to 24 microtiter wells and expanded to generate cell clones stably expressing different levels of avitag-Prox1.

\section{siRNA analysis}

Human dermal LECs (HDLECs) were purchased from PromoCell and cultured in endothelial basal medium (EBM) complemented with supplement mix (C-39225, PromoCell) according to the supplier's instructions. These cells were used between passages 2 and 6. HDLECs were transfected with ON-TARGETplus SMARTpool human for PROX1 (J-016913-08-0005), VEGFR3 (L003138-00-0005), or a control siRNA (D-001810-01-05) purchased from Dharmacon (Thermo Scientific). siRNA transfections (50 nM final concentration) were performed using Lipofectamine 2000 according to the manufacturer's recommendations. After $5 \mathrm{~h}$ of incubation, cells were rinsed twice with EBM and then incubated in complete EBM for an additional 24 and $48 \mathrm{~h}$ in the presence of $100 \mathrm{ng} / \mathrm{mL}$ recombinant Vegfc (R\&D Systems). The knockdown of endogenous Proxl and Vegfr3 was examined by Western blot analysis (data not shown), immunofluorescence, and qPCR.

\section{RNA isolation and quantification of gene expression}

Total RNA was extracted with the RNeasy minikit (Qiagen) according to the manufacturer's instructions. To quantify gene expression, $1 \mu \mathrm{g}$ of total RNA was used for cDNA synthesis (Clontech), and $1 \mu \mathrm{L}$ of cDNA was used for real-time PCR using LEC- and BEC-specific primers. Primer sequences are available in Supplemental Table 2. PCR (SYBR Green, ABI) analysis was performed on an Applied Biosystems 7500 real-time PCR system. Ct values for each gene were normalized to the endogenous control gene GAPDH using the $\Delta \Delta \mathrm{Ct}$ method. All experiments were performed in triplicate.

\section{Immunohistochemistry}

For immunohistochemical analysis, whole embryos were fixed in $4 \%$ PFA for $1 \mathrm{~h}$ at room temperature, embedded in $7 \%$ lowmelting agarose, sectioned on a vibratome $(100 \mu \mathrm{m})$, and immunostained. For immunohistochemical analysis of cryosections, embryos were fixed in $4 \%$ PFA overnight at $4^{\circ} \mathrm{C}$, embedded in OCT, sectioned in a cryostat $(10 \mu \mathrm{m})$, and immunostained. The sections were mounted using Prolong Gold mounting medium 
E9.5-13.5

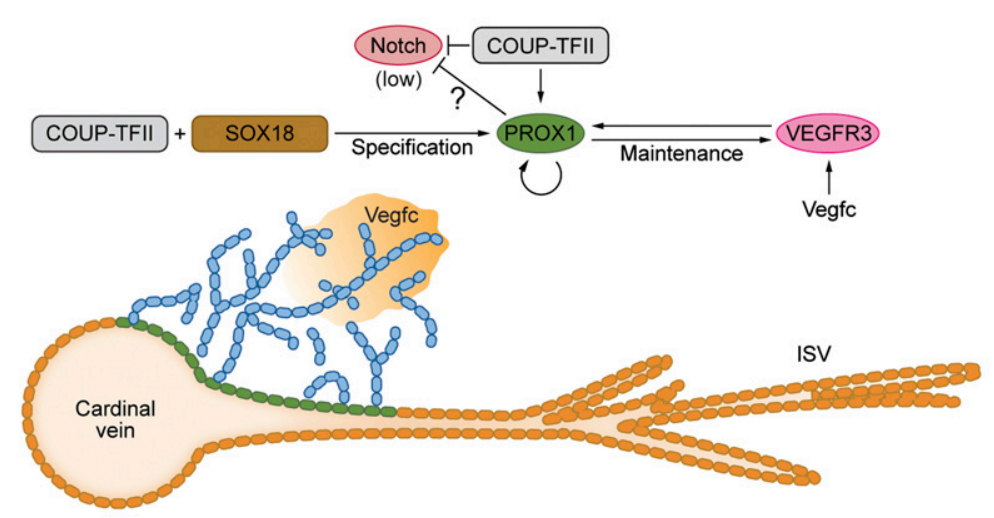

After E13.5
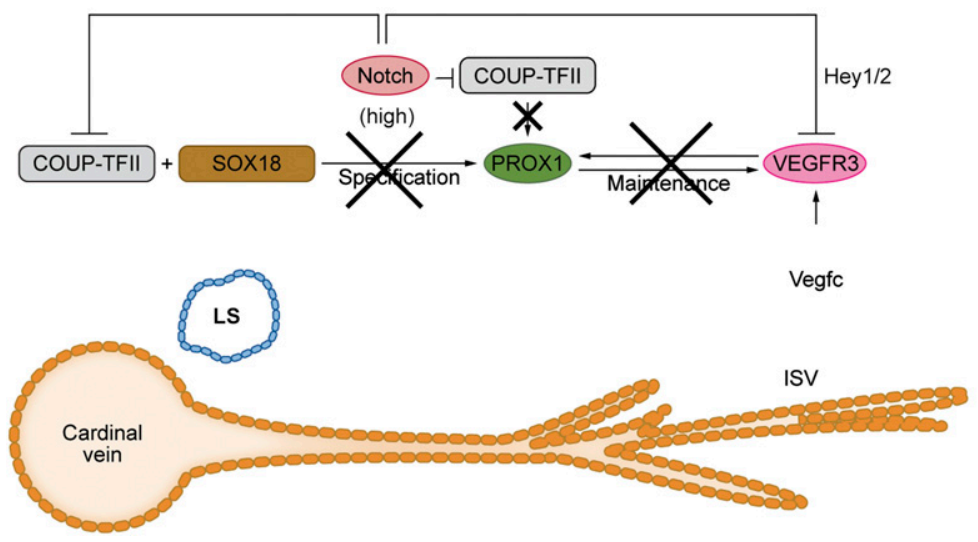

Venus ECs

LEC progenitors

Differentiating LECs

Figure 8. Model of the feedback loop regulating the specification of Proxl-expressing LEC progenitors in the embryonic veins. Between E9.75 and E13.5, in some venous EC cells with low or no Notch signaling, CoupTFII is up-regulated; then, in combination with Sox18, it induces Proxl expression such that LEC progenitors start to be specified. Notch signaling is repressed in the specified LEC progenitors by Coup-TFII. Proxl in turn activates the expression of Vegfr3 in a dosage-dependent manner. Activation of Vegfr3 signaling by Vegfe will also maintain Proxl expression in LEC progenitors and differentiating LECs. Coup-TFII also interacts with Proxl to maintain Prox1 expression. Coup-TFII and Proxl also likely maintain Notch signaling at low levels in LEC progenitors at this stage. Prox $1^{+}$LEC progenitors will subsequently bud off from the CV and intersomitic vessels (ISV) and start to express differentiation markers such as podoplanin. After E13.5, Notch signaling levels are increased in venous ECs such that Notch will suppress Coup-TFII to prevent further specification of Prox $1^{+}$LEC progenitors. At the same time, Notch signaling also likely inhibits Vegfr3 expression via Hey1/2, thereby short-circuiting the Prox1-Vegfr3 feedback loop and stopping the generation of LEC progenitors in the veins. It could be speculated that most likely the Prox1-Vegfr3 feedback loop does not operate in differentiated LECs.

containing DAPI (Life Technologies), and confocal microscopy was performed.

\section{Antibodies}

The following primary antibodies were used: rabbit anti- $\beta$-gal (MP Biomedicals), rabbit anti-Prox1 (AngioBio and ProteinTech Group), goat anti-Prox1 (R\&D Systems), hamster anti-podoplanin (Hybridoma Bank, Developmental Studies, University of Iowa), rat anti-PECAM1 (BD Pharmingen), goat anti-Vegfr3 (R\&D Systems), rabbit anti-GFP (Molecular Probes), and chicken antiGFP (Abcam). The following secondary antibodies were used: Alexa 488-conjugated donkey anti-rabbit (Molecular Probes), Alexa 488conjugated donkey anti-guinea pig (Molecular Probes), Alexa 488-conjugated goat anti-hamster (Molecular Probes), Alexa 488conjugated donkey anti-goat (Molecular Probes), Cy3-conjugated donkey anti-rabbit (Jackson ImmunoResearch Laboratories), Cy3- conjugated donkey anti-goat (Jackson ImmunoResearch Laboratories), and Cy5-conjugated donkey anti-rat (Jackson ImmunoResearch Laboratories).

\section{Image analysis}

Tissue sections prepared on a vibratome were immunostained with antibodies and then visualized with a confocal laser-scanning microscope (Zeiss LSM510). For images to be compared quantitatively, the same laser intensity settings were used, and images were acquired on the same day. Quantification of the fluorescence intensity was performed using Slidebook image analysis software.

\section{Statistical analysis}

Data analyses and statistical analyses were performed using Prism 5 software (Graph Pad Software, Inc.). Values are presented 
as group mean \pm SEM. For statistical analyses in siRNA experiments, we used one-way analysis of variance (ANOVA) followed by ANOVA test, followed by Bonferroni's multiple comparison test. $P$-values $<0.05$ were considered statistically significant $\left(P \leq 0.05\left[{ }^{\star}\right], P \leq 0.01\left[{ }^{\star \star}\right]\right.$, and $\left.P \leq 0.001\left[{ }^{\star \star \star}\right]\right)$. For experiments where intensity of fluorescence was measured, Microsoft Excel was used to evaluate the statistical significance by unpaired Student's $t$-test.

\section{ChIP}

Mouse primary LECs were isolated from E14.5 embryos by flow cytometry. Lyve- $1^{+}, \mathrm{CD} 31^{+}$, and CD $45^{-}$populations were used in the ChIP assay. ChIP was carried out with $10^{5}$ cells by using the LowCell ChIP kit (Diagenode). Rabbit anti-Proxl antibody (ProteinTech Group) and rabbit IgG were used in the ChIP. Following the pull-down and isolation of the chromatin fragments, real-time PCR was performed using primers that were specific for the multiple Proxl-binding sites and the nonspecific control site (data not shown).

\section{Whole-mount immunohistochemistry}

Whole-mount immunohistochemistry was performed as previously reported (James et al. 2013)

\section{Laser capture microdissection}

E11.5 Tg(Prox1-tdTomato) (wild type), Tg(Prox1-tdTomato); Prox $1^{+/ L a c Z}\left(\right.$ Prox $\left.^{+/-}\right)$, and Tg(Prox1-tdTomato); Vegfr3 $3^{+/ L a c Z}$ $\left(\right.$ Vegfr $\left.3^{+/-}\right)$embryos were generated and rapidly dissected at $4^{\circ} \mathrm{C}$ under RNase-free conditions. Embryos were fixed in $2 \%$ PFA for $15 \mathrm{~min}$ at $4^{\circ} \mathrm{C}$, washed twice with PBS, and frozen in $\mathrm{OCT}$ on dry ice immediately. The blocks were stored at $-80^{\circ} \mathrm{C}$ until sectioning in the cryostat. Sections were subsequently fixed for $30 \mathrm{sec}$ by immersion in cold methanol, dehydrated in graded ethanol solutions, and cleared in xylene. After air-drying, laser capture was performed under direct fluorescence microscopic visualization. Tomato ${ }^{+}$cells on the CV and Tomato ${ }^{+}$cells outside the $\mathrm{CV}$ were microdissected from the same frozen sections and kept separately. Cells were captured using ArcturusXT LCM instrument (Applied Biosystems). RNA was isolated using the RNeasy FFPE kit (Qiagen) followed by cDNA synthesis and amplification using Ovation Pico WTA System V2 (NuGEN) according to the manufacturer's instructions. RNA quality was assessed using a Bioanalyzer picochip (Agilent Technologies).

\section{Acknowledgments}

We thank Dr. Elizabetta Dejana for the $\mathrm{H}_{5} \mathrm{~V}$ cells, the members of our laboratories for their helpful suggestions and discussions, Dr. Angela McArthur for scientific editing of this manuscript, and Julie Gholson Groff for the generation of Figure 8. This work was supported by National Institutes of Health grant R01HL073402, the Leducq Foundation, and the American Lebanese Syrian Associated Charities (ALSAC) to G.O.

\section{References}

Aranguren XL, Beerens M, Coppiello G, Wiese C, Vandersmissen I, Nigro AL, Verfaillie CM, Gessler M, Luttun A. 2013. COUP-TFII orchestrates venous and lymphatic endothelial identity by homo- or heterodimerisation with PROX1. J Cell Sci 126: 1164-1175.

Chen CY, Bertozzi C, Zou Z, Yuan L, Lee JS, Lu M, Stachelek SJ, Srinivasan S, Guo L, Vicente A, et al. 2012. Blood flow reprograms lymphatic vessels to blood vessels. I Clin Invest 122: 2006-2017.

Dumont DJ, Jussila L, Taipale J, Lymboussaki A, Mustonen T, Pajusola K, Breitman M, Alitalo K. 1998. Cardiovascular failure in mouse embryos deficient in VEGF receptor-3. Science 282: 946-949.

Flister MJ, Wilber A, Hall KL, Iwata C, Miyazono K, Nisato RE, Pepper MS, Zawieja DC, Ran S. 2010. Inflammation induces lymphangiogenesis through up-regulation of VEGFR-3 mediated by NF-кB and Prox1. Blood 115: 418-429.

Francois M, Caprini A, Hosking B, Orsenigo F, Wilhelm D, Browne C, Paavonen K, Karnezis T, Shayan R, Downes M, et al. 2008. Sox18 induces development of the lymphatic vasculature in mice. Nature 456: 643-647.

Garlanda C, Parravicini C, Sironi M, De Rossi M, Wainstok de Calmanovici R, Carozzi F, Bussolino F, Colotta F, Mantovani A, Vecchi A. 1994. Progressive growth in immunodeficient mice and host cell recruitment by mouse endothelial cells transformed by polyoma middle-sized $\mathrm{T}$ antigen: implications for the pathogenesis of opportunistic vascular tumors. Proc Natl Acad Sci 91: 7291-7295.

Hagerling R, Pollmann C, Andreas M, Schmidt C, Nurmi H, Adams RH, Alitalo K, Andresen V, Schulte-Merker S, Kiefer F. 2013. A novel multistep mechanism for initial lymphangiogenesis in mouse embryos based on ultramicroscopy. EMBO $J$ 32: 629-644.

Harvey NL, Srinivasan RS, Dillard ME, Johnson NC, Witte MH, Boyd K, Sleeman MW, Oliver G. 2005. Lymphatic vascular defects promoted by Prox1 haploinsufficiency cause adultonset obesity. Nat Genet 37: 1072-1081.

Hong YK, Harvey N, Noh YH, Schacht V, Hirakawa S, Detmar M, Oliver G. 2002. Proxl is a master control gene in the program specifying lymphatic endothelial cell fate. Dev Dyn 225: 351-357.

Iljin K, Karkkainen MJ, Lawrence EC, Kimak MA, Uutela M, Taipale J, Pajusola K, Alhonen L, Halmekyto M, Finegold DN et al. 2001. VEGFR3 gene structure, regulatory region, and sequence polymorphisms. FASEB J 15: 1028-1036.

James JM, Nalbandian A, Mukouyama YS. 2013. TGF $\beta$ signaling is required for sprouting lymphangiogenesis during lymphatic network development in the skin. Development 140: 3903-3914.

Jeltsch M, Jha SK, Tvorogov D, Anisimov A, Leppanen VM, Holopainen T, Kivela R, Ortega S, Karpanen T, Alitalo K. 2014. CCBE1 enhances lymphangiogenesis via a disintegrin and metalloprotease with thrombospondin motifs-3-mediated vascular endothelial growth factor-C activation. Circulation 129: 1962-1971.

Jeong J, Mao J, Tenzen T, Kottmann AH, McMahon AP. 2004. Hedgehog signaling in the neural crest cells regulates the patterning and growth of facial primordia. Genes Dev 18: 937-951.

Johnson NC, Dillard ME, Baluk P, McDonald DM, Harvey NL, Frase SL, Oliver G. 2008. Lymphatic endothelial cell identity is reversible and its maintenance requires Proxl activity. Genes Dev 22: 3282-3291.

Kaipainen A, Korhonen J, Mustonen T, van Hinsbergh VW, Fang GH, Dumont D, Breitman M, Alitalo K. 1995. Expression of the fms-like tyrosine kinase 4 gene becomes restricted to lymphatic endothelium during development. Proc Natl Acad Sci 92: 3566-3570.

Karkkainen MJ, Haiko P, Sainio K, Partanen J, Taipale J, Petrova TV, Jeltsch M, Jackson DG, Talikka M, Rauvala H, et al. 2004. Vascular endothelial growth factor $\mathrm{C}$ is required for sprouting of the first lymphatic vessels from embryonic veins. Nat Immunol 5: 74-80. 
Lee S, Kang J, Yoo J, Ganesan SK, Cook SC, Aguilar B, Ramu S, Lee J, Hong YK. 2009. Proxl physically and functionally interacts with COUP-TFII to specify lymphatic endothelial cell fate. Blood 113: 1856-1859.

Lin FJ, Chen X, Qin J, Hong YK, Tsai MJ, Tsai SY. 2010. Direct transcriptional regulation of neuropilin-2 by COUP-TFII modulates multiple steps in murine lymphatic vessel development. I Clin Invest 120: 1694-1707.

Matys V, Kel-Margoulis OV, Fricke E, Liebich I, Land S, BarreDirrie A, Reuter I, Chekmenev D, Krull M, Hornischer K, et al. 2006. TRANSFAC and its module TRANSCompel: transcriptional gene regulation in eukaryotes. Nucleic Acids Res 34: D108-D110.

Mishima K, Watabe T, Saito A, Yoshimatsu Y, Imaizumi N, Masui S, Hirashima M, Morisada T, Oike Y, Araie M, et al. 2007. Prox1 induces lymphatic endothelial differentiation via integrin $\alpha 9$ and other signaling cascades. Mol Biol Cell 18: $1421-1429$.

Murtomaki A, Uh MK, Choi YK, Kitajewski C, Borisenko V, Kitajewski J, Shawber CJ. 2013. Notch1 functions as a negative regulator of lymphatic endothelial cell differentiation in the venous endothelium. Development 140: 2365-2376.

Muzumdar MD, Tasic B, Miyamichi K, Li L, Luo L. 2007. A global double-fluorescent Cre reporter mouse. Genesis 45: 593-605.

Nakayama M, Nakayama A, van Lessen $M$, Yamamoto $H$, Hoffmann S, Drexler HC, Itoh $\mathrm{N}$, Hirose $\mathrm{T}$, Breier $\mathrm{G}$, Vestweber D, et al. 2013. Spatial regulation of VEGF receptor endocytosis in angiogenesis. Nat Cell Biol 15: 249-260.

Norrmen C, Ivanov KI, Cheng J, Zangger N, Delorenzi M, Jaquet M, Miura N, Puolakkainen P, Horsley V, Hu J, et al. 2009. FOXC2 controls formation and maturation of lymphatic collecting vessels through cooperation with NFATc1. I Cell Biol 185: 439-457.

Pan MR, Chang TM, Chang HC, Su JL, Wang HW, Hung WC. 2009. Sumoylation of Proxl controls its ability to induce VEGFR3 expression and lymphatic phenotypes in endothelial cells. J Cell Sci 122: 3358-3364.

Petrova TV, Makinen T, Makela TP, Saarela J, Virtanen I, Ferrell RE, Finegold DN, Kerjaschki D, Yla-Herttuala S, Alitalo K. 2002. Lymphatic endothelial reprogramming of vascular endothelial cells by the Prox-1 homeobox transcription factor. EMBO I 21: 4593-4599.

Petrova TV, Karpanen T, Norrmen C, Mellor R, Tamakoshi T, Finegold D, Ferrell R, Kerjaschki D, Mortimer P, Yla-Herttuala S, et al. 2004. Defective valves and abnormal mural cell recruitment underlie lymphatic vascular failure in lymphedema distichiasis. Nat Med 10: 974-981.

Soriano P. 1999. Generalized lacZ expression with the ROSA26 Cre reporter strain. Nat Genet 21: 70-71.

Srinivasan RS, Oliver G. 2011. Proxl dosage controls the number of lymphatic endothelial cell progenitors and the formation of the lymphovenous valves. Genes Dev 25: 21872197.

Srinivasan RS, Dillard ME, Lagutin OV, Lin FJ, Tsai S, Tsai MJ, Samokhvalov IM, Oliver G. 2007. Lineage tracing demonstrates the venous origin of the mammalian lymphatic vasculature. Genes Dev 21: 2422-2432.

Srinivasan RS, Geng X, Yang Y, Wang Y, Mukatira S, Studer M, Porto MP, Lagutin O, Oliver G. 2010. The nuclear hormone receptor Coup-TFII is required for the initiation and early maintenance of Proxl expression in lymphatic endothelial cells. Genes Dev 24: 696-707.

Tammela T, Zarkada G, Wallgard E, Murtomaki A, Suchting S, Wirzenius M, Waltari M, Hellstrom M, Schomber T, Peltonen $\mathrm{R}$, et al. 2008. Blocking VEGFR-3 suppresses angiogenic sprouting and vascular network formation. Nature 454: 656660.

Truman LA, Bentley KL, Smith EC, Massaro SA, Gonzalez DG, Haberman AM, Hill M, Jones D, Min W, Krause DS, et al. 2012. ProxTom lymphatic vessel reporter mice reveal Prox1 expression in the adrenal medulla, megakaryocytes, and platelets. Am J Pathol 180: 1715-1725.

Wigle JT, Oliver G. 1999. Prox1 function is required for the development of the murine lymphatic system. Cell 98: 769778.

Wigle JT, Chowdhury K, Gruss P, Oliver G. 1999. Proxl function is crucial for mouse lens-fibre elongation. Nat Genet 21: 318-322.

Wigle JT, Harvey N, Detmar M, Lagutina I, Grosveld G, Gunn MD, Jackson DG, Oliver G. 2002. An essential role for Prox1 in the induction of the lymphatic endothelial cell phenotype. EMBO I 21: 1505-1513.

Yamazaki T, Yoshimatsu Y, Morishita Y, Miyazono K, Watabe T. 2009. COUP-TFII regulates the functions of Proxl in lymphatic endothelial cells through direct interaction. Genes Cells 14: 425-434.

Yang Y, Garcia-Verdugo JM, Soriano-Navarro M, Srinivasan RS, Scallan JP, Singh MK, Epstein JA, Oliver G. 2012. Lymphatic endothelial progenitors bud from the cardinal vein and intersomitic vessels in mammalian embryos. Blood 120: 2340-2348.

You LR, Lin FJ, Lee CT, DeMayo FJ, Tsai MJ, Tsai SY. 2005. Suppression of Notch signalling by the COUP-TFII transcription factor regulates vein identity. Nature 435: 98-104.

Zhang L, Zhou F, Han W, Shen B, Luo J, Shibuya M, He Y. 2010. VEGFR-3 ligand-binding and kinase activity are required for lymphangiogenesis but not for angiogenesis. Cell Res 20: 1319-1331. 


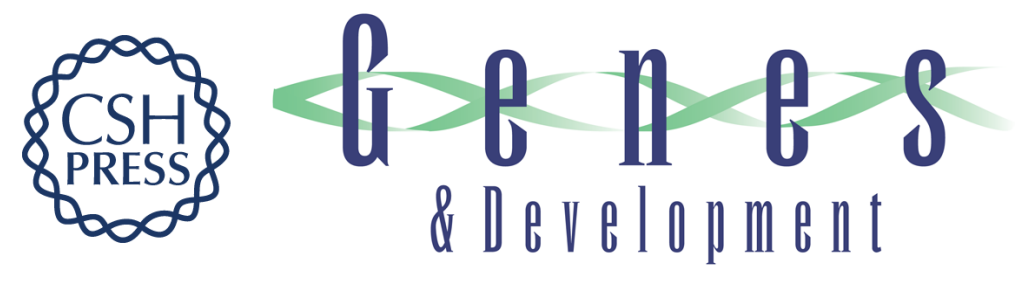

\section{The Prox1-Vegfr3 feedback loop maintains the identity and the number of lymphatic endothelial cell progenitors}

R. Sathish Srinivasan, Noelia Escobedo, Ying Yang, et al.

Genes Dev. 2014, 28:

Access the most recent version at doi:10.1101/gad.216226.113

Supplemental http://genesdev.cshlp.org/content/suppl/2014/09/29/28.19.2175.DC1
Material

References This article cites 40 articles, 21 of which can be accessed free at:

http://genesdev.cshlp.org/content/28/19/2175.full.html\#ref-list-1

Creative This article is distributed exclusively by Cold Spring Harbor Laboratory Press for the first Commons six months after the full-issue publication date (see

License http://genesdev.cshlp.org/site/misc/terms.xhtml). After six months, it is available under a Creative Commons License (Attribution-NonCommercial 4.0 International), as described at http://creativecommons.org/licenses/by-nc/4.0/.

Email Alerting Receive free email alerts when new articles cite this article - sign up in the box at the top Service right corner of the article or click here.

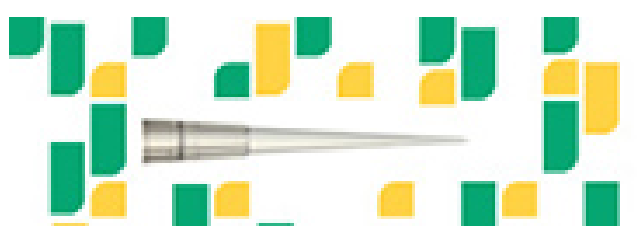

Focused on your science. 